\title{
Pain Interference Subordinate Domain
}

National Cancer Institute

\section{Source}

National Cancer Institute. Pain Interference Subordinate Domain. NCI Thesaurus. Code C125619.

The collection of PROMIS item scales that assess the consequences of pain on relevant aspects of a person's life, including the impact of pain on social, cognitive, emotional, physical, and recreational activities as well as sleep and enjoyment in life. 